\title{
Sosialisasi Pemanfaatan Herbal Bumbu Dapur sebagai Antihipertensi dan Pemeriksaan Tekanan Darah di Desa Kandangan Baru Kecamatan Panyipatan Tanah Laut
}

\author{
Karina Erlianti ${ }^{1}$, Juwita Ramadhani ${ }^{2}$, Aris Fadillah ${ }^{3}$, Hasniah $^{5}$, Didi Susanto ${ }^{5}$, Muhammad Fauzi ${ }^{6}$, \\ Fauzi Rahman ${ }^{7}$ \\ Farmasi, Universitas Islam Kalimantan Muhammad Arsyad Al-Banjary, Indonesia 1,2,3,4,5,6,7 \\ E-mail: karina.erlianti@gmail.com ${ }^{1}$, juwitarha@gmail.com ${ }^{2}, \underline{\text { aris.f.6593@gmail.com }}^{3}$, \\ hasniahhapt@gmail.com ${ }^{4}$, didisusanto82@yahoo.do.id ${ }^{5}$, fauzi.ozi1294@ gmail.com6 6 , \\ fauzi.rahmanpharmacy@gmail.com ${ }^{7}$
}

\begin{abstract}
Abstrak
Beberapa jenis bumbu dapur yang digunakan sehari-hari terbukti memiliki zat yang berkhasiat untuk menurunkan tekanan darah. Kurangnya pengetahuan mengenai penggunaan herbal yang benar menyebabkan tidak tercapainya khasiat yang diinginkan. Jumlah penduduk Desa Kandangan Baru yang diukur tekanan darahnya masih sedikit jika dibandingkan dengan jumlah total seluruh penduduk Desa Kandangan Baru. Pelaksanaan kegiatan pengabdian masyarakat ini bertujuan untuk menyelenggarakan deteksi dini terjadinya hipertensi serta memberikan pengetahuan kepada masyarakat mengenai cara penggunaan herbal sebagai terapi pencegahan alternatif yang benar. Metode yang digunakan yaitu pemberian penyuluhan tentang pemanfaatan bumbu dapur yang benar serta pemeriksaan tekanan darah. Desain pretest dan post-test digunakan sebagai pengukur. Terjadi peningkatan skor pada peserta sebanyak $90 \%$ dengan dari poin rata-rata 4,95 pada pretest menjadi 9,39 saat post-test. Diketahui sebanyak 18 orang memiliki tekanan darah di atas 120/80 mmHg dimana 3 orang di antaranya masih belum melakukan pengecekan rutin dan tidak dalam terapi hipertensi. Dapat disimpulkan bahwa kegiatan ini secara efektif dapat meningkatkan pengetahuan masyarakat mengenai pemanfaatan herbal bumbu dapur sebagai terapi alternatif hipertensi dan dapat terdeteksinya hipertensi. Deteksi dini hipertensi serta penggunaan bumbu dapur sebagai terapi pencegahan yang benar sangat penting untuk mencegah terjadinya komplikasi akibat hipertensi yang tidak diterapi serta meningkatkan tingkat kesehatan masyarakat desa.
\end{abstract}

Kata kunci: herbal, bumbu dapur, hipertensi

\section{Abstract}

Several seasoning spices that used on daily basis were proven to have blood pressure-lowering properties. The lack of information about the proper way to use these spices resulting in ineffectiveness. The number of people in Kandangan Baru village which have their blood pressure checked regularly is low compared to its total population. The purpose of this public service activity is to conduct an early detection of hypertension and provide the information about the proper way of using the spices for alternative prevention therapy. The method used in this activity including the explanation about how to properly use herbs spices and the measurement of the blood pressure for all participants. Pretest and posttest design were used for measurement. There was an increase of score in a total of $90 \%$ of participant with the average score of 4,95 for pre-test to 9,39 for post-test. 18 participants have blood pressure over 120/80 $\mathrm{mmHg}$ and 3 of them was not checked regularly and not in any therapy. In conclusion, this activity effectively increasing the participant understanding about the proper way to use the herbs spices and the detection of hypertension. An early detection of hypertension and the proper way of herbs spices for prevention are very necessary to prevent the complication due the untreated hypertension and also improving the village public health.

Keywords: herbs, seasoning spices, hypertension

Copyright (c) 2021 Karina Erlianti, Juwita Ramadhani, Aris Fadillah, Hasniah, Didi Susanto Muhammad Fauzi, Fauzi Rahman

$\triangle$ Corresponding author

Address : Universitas Islam Kalimantan MAB

Email : karina.erlianti@gmail.com

DOI : https://doi.org/10.31004/abdidas.v2i3.311

ISSN 2721- 9224 (Media Cetak)

ISSN 2721- 9216 (Media Online) 
506 Sosialisasi Pemanfaatan Herbal Bumbu Dapur sebagai Antihipertensi dan Pemeriksaan Tekanan Darah di Desa Kandangan Baru Kecamatan Panyipatan Tanah Laut - Karina Erlianti, Juwita Ramadhani, Aris Fadillah, Hasniah, Didi Susanto, Muhammad Fauzi, Fauzi Rahman

DOI: https://doi.org/10.31004/abdidas.v2i3.311

\section{PENDAHULUAN}

Herbal merupakan bahan atau produk yang berasal dari tumbuhan yang bermanfaat dalam pengobatan dan kesehatan manusia. Pemanfaatan beberapa herbal yang biasanya digunakan untuk bumbu dapur sebagai obat tradisional sudah dilakukan sejak dulu dan terus meningkat dalam beberapa tahun terakhir. Hal ini salah satunya disebabkan karena harga obat tradisional yang dianggap lebih terjangkau dan efek sampingnya dianggap lebih minimal oleh masyarakat (Hussaana et al., 2016).

Persentase penduduk Indonesia yang menggunakan obat tradisional terus meningkat. Data Riskerdas tahun 2018 menunjukkan bahwa penduduk Indonesia melakukan pengobatan menggunakan ramuan jadi obat tradisional sebanyak 48\%, menggunakan obat tradisional ramuan sendiri $31,8 \%$ dan memanfaatkan Pelayanan Kesehatan Tradisional sebanyak 31,4\% (Kemenkes RI, 2019). Meningkatnya tren penggunaan obat tradisional ini dikuti dengan maraknya beragam informasi yang menyebar di masyarakat terkait obat herbal yang sebagian tidak dapat dipertanggungjawabkan kebenarannya. Umumnya, obat tradisional dinilai lebih minimal efek samping sehingga dianggap lebih aman digunakan dari pada penggunaan obat modern, namun obat tradisional juga dapat menimbulkan efek samping dan tidak menimbulkan efek terapi karena disebabkan oleh minimnya pengetahuan masyarakat tentang aturan dan cara pakai obat tradisional yang baik seperti takaran dosis dan interaksinya dengan obat kimia (Sidoretno \& Rz
Oktaviani, 2018), Hasil wawancara kepada tokoh masyarakat Desa Kandangan Baru menunjukkan bahwa Desa Kandangan Baru memiliki penduduk yang memiliki kepercayaan yang tinggi terhadap obat herbal, namun pengetahuan mengenai ketepatan dalam menggunakan obat herbal masih rendah.

Hipertensi merupakan penyakit tidak menular yang dapat mempengaruhi kualitas hidup seseorang. Data Riset Kesehatan Dasar (Riskerdas) tahun 2018 menunjukkan Kalimantan Selatan merupakan provinsi dengan prevalensi hipertensi tertinggi di Indonesia dengan persentase 44,13\% (Kemenkes RI, 2019). Di Desa Kandangan Baru berdasarkan data hasil pengukuran tekanan darah yang dilakukan oleh tenaga kesehatan di Puskesmas Pembantu, dari 60 orang penduduk yang diukur tekanan darahnya terdapat 49 orang yang memiliki tekanan darah tinggi (82\%). Jumlah penduduk Desa Kandangan Baru yang diukur tekanan darahnya masih sedikit jika dibandingkan dengan jumlah total seluruh penduduk Desa Kandangan Baru yang berusia diatas 18 tahun.

Terkait dengan permasalahan tersebut, maka tim pelaksana ingin melakukan pengabdian kepada masyarakat dengan tema "Sosialisasi Pemanfaatan Herbal Bumbu Dapur sebagai Antihipertensi dan Pemeriksaan Tekanan Darah di Desa Kandangan Baru Kecamatan Panyipatan Tanah Laut". Herbal bumbu dapur merupakan tanaman berkhasiat obat yang mudah didapatkan di rumah dan biasanya selalu ada karena juga digunakan untuk memasak seperti seledri, daun salam, ketumbar, bawang putih, kunyit yang dapat digunakan untuk 
507 Sosialisasi Pemanfaatan Herbal Bumbu Dapur sebagai Antihipertensi dan Pemeriksaan Tekanan Darah di Desa Kandangan Baru Kecamatan Panyipatan Tanah Laut - Karina Erlianti, Juwita Ramadhani, Aris Fadillah, Hasniah, Didi Susanto, Muhammad Fauzi, Fauzi Rahman

DOI: https://doi.org/10.31004/abdidas.v2i3.311

menurunkan tekanan darah. Sosialisasi kepada masyarakat mengenai penggunaan obat herbal dengan tepat dan bijak harus dilakukan dengan memberikan informasi mengenai dosis dan aturan pakai yang tepat, ketepatan menggali informasi serta ketepatan pemilihan obat agar herbal yang digunakan menimbulkan efek terapi yang diinginkan dan tidak menimbulkan efek samping (Sumayyah \& Salsabila, 2017). Pengukuran tekanan darah di Desa Kandangan Baru juga perlu dilakukan karena Hipertensi merupakan penyakit yang dapat membunuh diam-diam dan dapat tidak disadari oleh penderitanya terutama pada masyarakat yang memiliki faktor risiko.

\section{METODE}

Metode yang digunakan dalam pelaksanaan kegiatan pengabdian masyarakat ini adalah: a) pendidikan masyarakat, dengan memberikan penyuluhan secara langsung mengenai tanaman herbal bumbu dapur sebagai antihipertensi disertai diskusi bersama ibu-ibu anggota PKK Desa Kandangan Baru. b) pengadaan media promosi kesehatan berupa brosur, poster dan banner dengan desain yang menarik terkait materi penyuluhan. c) pemeriksaan tekanan darah.

Kegiatan ini dimulai dengan survei dan observasi, penyusunan program, persiapan pelaksanaan, pelaksanaan kegiatan dan evaluasi. Proses survei dan observasi serta penyusunan program dan persiapan pelaksanaan kegiatan dilakukan pada bulan Desember 2020 sampai dengan bulan Januari 2021. Pelaksanaan kegiatan pengabdian masyarakat dilakukan dengan metode penyuluhan yang diselenggarakan pada hari Sabtu tanggal 20 Februari 2021 bertempat di Aula Balai Desa Kandangan Baru Kecamatan Panyipatan Kabupaten Tanah Laut. Proses evaluasi dilakukan dengan memberikan pretest dan post-test pada hari pelaksanaan kegiatan untuk mengetahui pengetahuan masyarakat sebelum dan setelah diberikan penyuluhan.

Khalayak sasaran pada kegiatan ini adalah ibu-ibu anggota PKK Desa Kandangan Baru sebanyak 23 dari 40 orang anggota. Anggota PKK Desa Kandangan Baru yang terpilih untuk mengikuti kegiatan ini adalah yang memiliki tekanan darah lebih dari 120/80 mmHg. Seleksi peserta kegiatan dilakukan dengan tujuan agar saat pelaksanaan kegiatan peserta dan tim pelaksana tetap dapat menjaga jarak dan mematuhi protokol kesehatan karena kegiatan dilaksanakan pada saat pandemi Covid-19.

\section{HASIL DAN PEMBAHASAN}

Kegiatan sosialisasi pemanfaatan herbal bumbu dapur sebagai terapi alternatif hipertensi telah dilaksanakan dengan peserta penyuluhan adalah ibu-ibu anggota PKK Desa Kandangan Baru sebanyak 23 orang. Sebelum kegiatan sosialisasi dilaksanakan, tim pelaksana melakukan studi pendahuluan dengan mencari informasi melalui bidan desa mengenai prevalensi hipertensi di Desa Kandangan Baru, survei jenis herbal bumbu dapur berkhasiat antihipertensi yang tersedia di rumah anggota PKK Desa Kandangan Baru dan melihat ketersediaan tanaman herbal berkhasiat antihipertensi yang ditanam pada 
508 Sosialisasi Pemanfaatan Herbal Bumbu Dapur sebagai Antihipertensi dan Pemeriksaan Tekanan Darah di Desa Kandangan Baru Kecamatan Panyipatan Tanah Laut - Karina Erlianti, Juwita Ramadhani, Aris Fadillah, Hasniah, Didi Susanto, Muhammad Fauzi, Fauzi Rahman

DOI: https://doi.org/10.31004/abdidas.v2i3.311

halaman balai Desa Kandangan Baru. Selain itu, tim pelaksana juga melakukan pengukuran tekanan darah pada anggota PKK Desa Kandangan Baru untuk menentukan peserta penyuluhan. Kegiatan sosialisasi pemanfaatan herbal bumbu dapur sebagai terapi alternatif hipertensi kemudian dilaksanakan pada hari Sabtu tanggal 20 Februari 2021. Kegiatan sosialisasi diawali dengan pretest. Tim pelaksana memberikan pretest kepada peserta sosialsiasi yang bertujuan untuk mengukur pengetahuan sebelum diberikan sosialisasi. Kegiatan dilanjutkan dengan pemberian materi mengenai pemanfaatan bumbu dapur sebagai alternatif terapi hipertensi menggunakan media brosur dan power point. Setelah pemberian materi dilakukan, pelaksana berdiskusi dan melakukan tanya jawab dengan peserta pengabdian mengenai materi yang telah disampaikan. Sosialisasi kemudian diakhiri dengan post-test untuk mengetahui perubahan tingkat pengetahuan peserta kegiatan mengenai pemanfaatan herbal bumbu dapur sebagai terapi alternatif hipertensi setelah pemberian materi. Kegiatan selanjutnya adalah pemeriksaan tekanan darah oleh pelaksana kepada peserta kegiatan.

Selama kegiatan dilaksanakan peserta terlihat antusias dalam mengkuti seluruh rangkaian acara. Mulai dari senam jantung yang dilakukan dengan semangat dan ceria. Seluruh peserta mengikuti sosialisasi dengan tertib dan menyimak dengan baik hal-hal yang disampaikan oleh pemateri. Diskusi juga terjadi antara pemateri dan ibu-ibu anggota PKK Desa Kandangan Baru. Ibuibu anggota PKK banyak mengajukan berbagai pertanyaan seputar hipertensi dan herbal-herbal bumbu dapur yang bisa menurunkan tekanan darah.

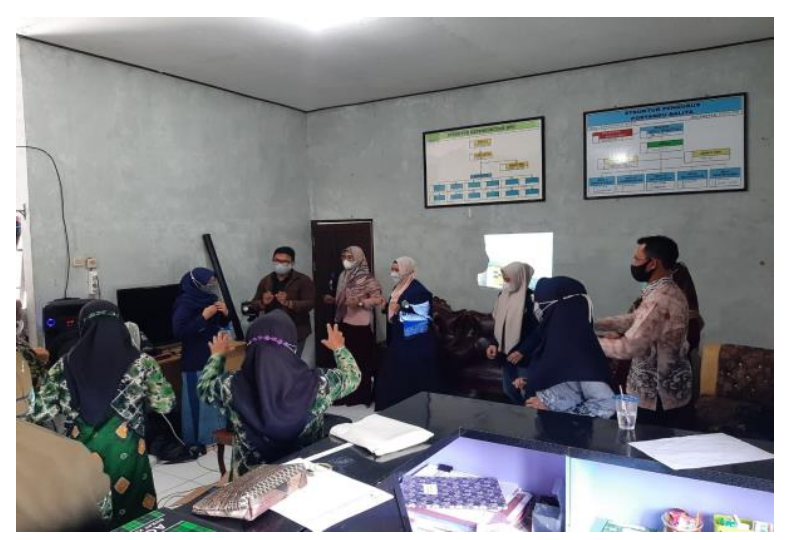

Gambar 1. Senam Jantung Bersama

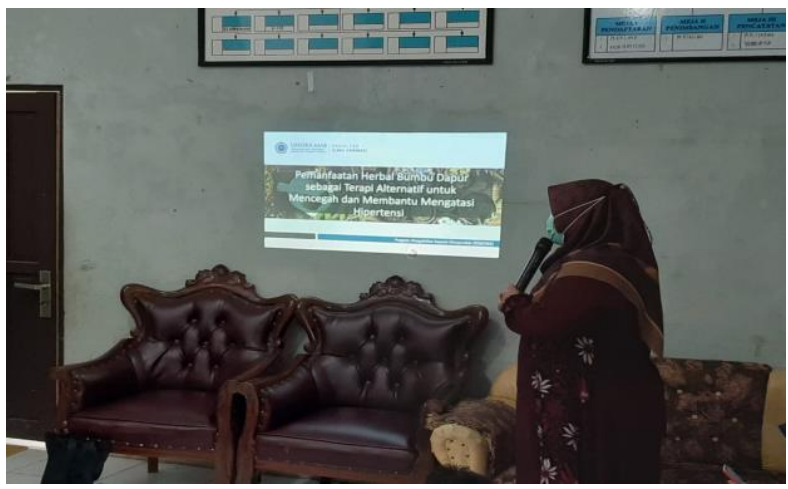

Gambar 2. Penyampaian Materi

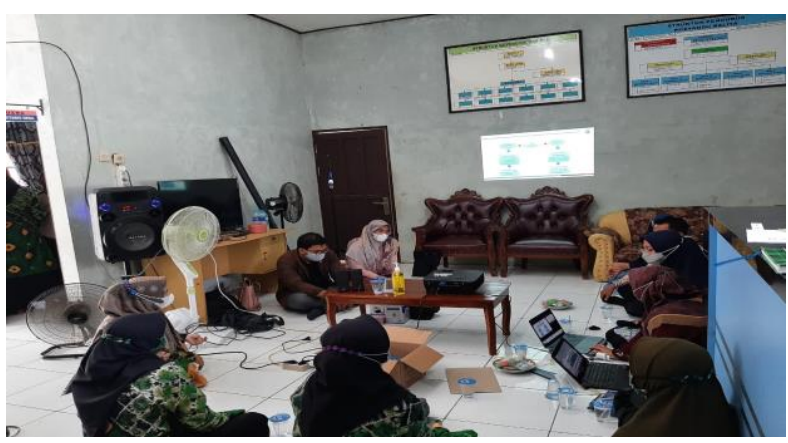

Gambar 3. Sesi Diskusi

Materi yang disampaikan pada kegiatan ini bermanfaat untuk meningkatkan pengetahuan ibuibu anggota PKK mengenai hipertensi, macammacam herbal bumbu dapur yang dapat digunakan 
509 Sosialisasi Pemanfaatan Herbal Bumbu Dapur sebagai Antihipertensi dan Pemeriksaan Tekanan Darah di Desa Kandangan Baru Kecamatan Panyipatan Tanah Laut - Karina Erlianti, Juwita Ramadhani, Aris Fadillah, Hasniah, Didi Susanto, Muhammad Fauzi, Fauzi Rahman

DOI: https://doi.org/10.31004/abdidas.v2i3.311

untuk terapi alternatif hipertensi, cara mengolah herbal tersebut dengan tepat, interaksi herbal bumbu dapur tersebut dengan obat dan herbal lain nya, efek samping serta kontra indikasi dari setiap herbal bumbu dapur terapi alternatif hipertensi tersebut. Setelah sosialisasi dilaksanakan peserta mengetahui tentang hipertensi serta macammacam herbal bumbu dapur yang dapat digunakan untuk hipertensi beserta ketepatan cara penggunaannya. Pemeriksaan tekanan darah kemudian dilakukan untuk mengetahui tekanan darah ibu-ibu PKK saat itu, kemudian pelaksana memberikan konseling mengenai terapi hipertensi agar tekanan darah tetap terkontrol. Hasil pengukuran tekanan darah kepada peserta kegiatan menunjukkan bahwa 5 orang memiliki tekanan darah sebesar 120-139/80-89 mmHg, 11 orang memiliki tekanan darah sebesar 140-159/90-99 mmHg dimana 8 orang diantaranya telah rutin meminum obat antihipertensi dan 7 orang memiliki tekanan darah $\geq 160 / \geq 100 \mathrm{mmHg}$ dan telah rutin meminum obat antihipertensi.

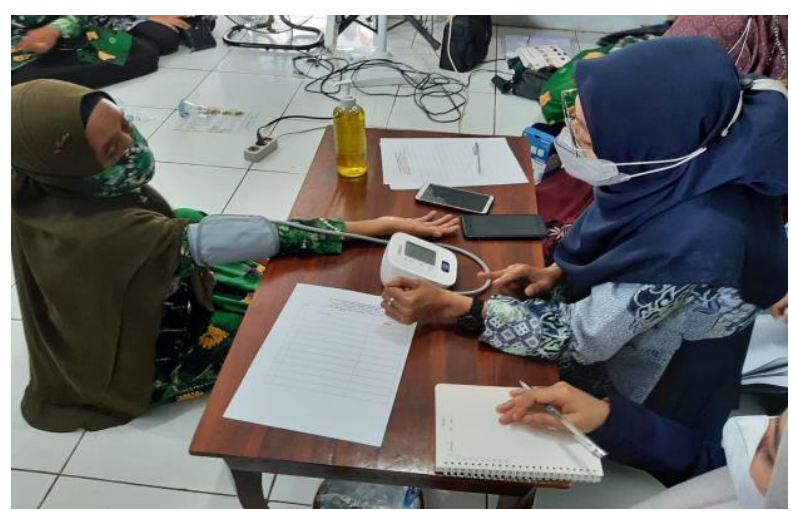

Gambar 4. Pemeriksaan Tensi

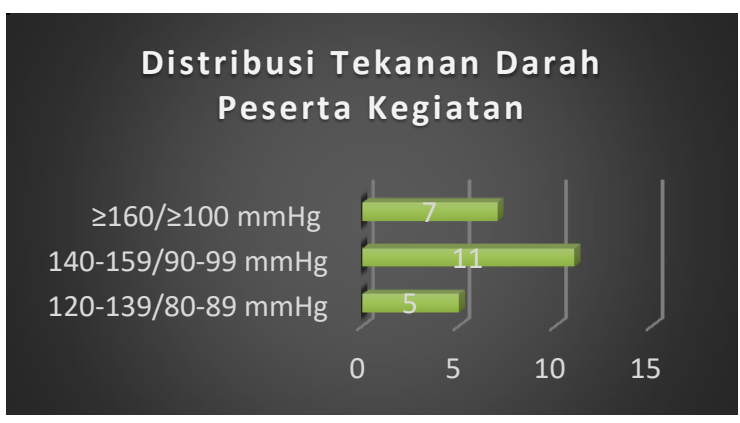

Gambar 5. Distribusi Tekanan Darah Peserta

Hasil dari kegiatan ini menunjukkan adanya peningkatan pengetahuan peserta kegiatan mengenai pemanfaatan herbal bumbu dapur yang dapat digunakan sebagai terapi alternatif hipertensi seperti yang tercantum dalam gambar 6 . Perbandingan hasil post-test dan pretest yang meningkat sebanyak $90 \%$ yaitu dari rata-rata skor 4,95 pada pretest menjadi 9,39 saat post-test sehingga dapat dikatakan bahwa kegiatan ini dapat meningkatkan pengetahuan masyarakat mengenai hipertensi, macam-macam herbal bumbu dapur yang dapat digunakan untuk terapi alternatif hipertensi, cara mengolah herbal tersebut dengan tepat, interaksi herbal bumbu dapur tersebut dengan obat dan herbal lainnya, efek samping serta kontra indikasi dari setiap herbal bumbu dapur terapi alternatif hipertensi tersebut.

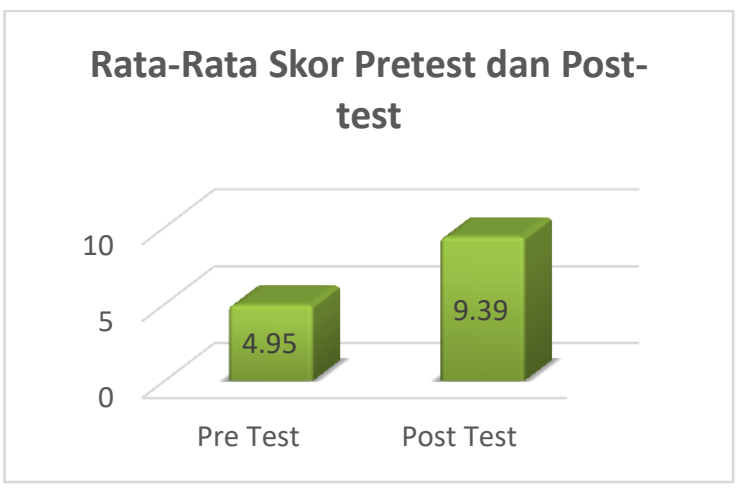

Gambar 6. Rata-rata Skor Pretest dan Post-test 
510 Sosialisasi Pemanfaatan Herbal Bumbu Dapur sebagai Antihipertensi dan Pemeriksaan Tekanan Darah di Desa Kandangan Baru Kecamatan Panyipatan Tanah Laut - Karina Erlianti, Juwita Ramadhani, Aris Fadillah, Hasniah, Didi Susanto, Muhammad Fauzi, Fauzi Rahman

DOI: https://doi.org/10.31004/abdidas.v2i3.311

Pengabdian masyarakat sebelumnya yang berjudul penyuluhan penggunaan obat tradisional kepada lansia Puskesmas Palanro Kabupaten Baru menunjukkan bahwa kegiatan penyuluhan masyarakat yang dilakukan memberikan peningkatan pengetahuan peserta penyuluhan mengenai obat tradisional, yang ditandai dengan hasul kuesioner yang baik dengan rata-rata 76,5 (Stevani et al., 2020). Pengabdian masyarakat yang dilakukan di Bojonegoro dengan judul Penyuluhan Swamedikasi Obat Herbal di PKK Kecamatan dan Kabupaten Bojonegoro juga menunjukkan terjadi peningkatan pengetahuan peserta penyuluhan sebelum dan sesudah diberikan materi (Setianto et al., 2021). Peningkatan pengetahuan pada masyarakat untuk menggunakan obat tradisional secara tepat dan aman tergambar pada pengabdian masyarakat lainnya yang berjudul ketepatan penggunaan obat tradisional serta pengalaman penyuluhan di lingkungan RW 02 dan RW 03 Kelurahan Jati Padang, Jakarta Selatan (Elenora \& Ristiawati, 2019).

\section{SIMPULAN}

Berdasarkan hasil di atas, kegiatan pengabdian masyarakat ini dapat meningkatkan pengetahuan masyarakat mengenai pemanfaatan herbal bumbu dapur sebagai terapi alternatif pencegahan hipertensi serta dapat mendeteksi terjadinya hipertensi secara efektif. Deteksi dini hipertensi serta penggunaan bumbu dapur sebagai terapi pencegahan yang benar sangat penting untuk mencegah terjadinya komplikasi akibat hipertensi yang tidak diterapi.
Peserta yang merupakan anggota PKK di desa tersebut diharapkan dapat menerapkan pengetahuan yang telah didapat dari kegiatan ini, serta dapat menjadi kader dalam memberikan informasi tersebut kepada masyarakat sehingga dapat berperan serta dalam meningkatkan tingkat kesehatan masyarakat desa.

\section{UCAPAN TERIMAKASIH}

Terimakasih disampaikan kepada kepala desa, ketua PKK dan masyarakat terutama anggota PKK Desa Kandangan Baru, Kecamatan Panyipatan, Tanah laut Kalimantan Selatan, yang telah memberikan kesempatan, serta memberikan waktu dan tempat kepada tim pelaksana sehingga kegiatan sosialisasi pemanfaatan herbal bumbu dapur sebagai terapi alternatif hipertensi dan pemeriksaan tekanan darah ini dapat terselenggara dengan baik dan lancar.

\section{DAFTAR PUSTAKA}

Elenora, R., \& Ristiawati, N. (2019). Ketepatan Penggunaan Obat Tradisional serta Pengalaman Penyuluhan di Lingkungan RW 02 dan RW 03 Kelurahan Jatipadang Jakarta Selatan. Bulletin Dharmanesti Niramaya ..., 1(1), 10-13. https://perpus.poltekkesjkt2.ac.id/tabloit/inde x.php/bdn_jur1/article/view/22

Hussaana, A., Sarosa, H., Indrayani, U. D., Chodidjah, C., Widiyanto, B., \& Pertiwi, D. (2016). Formula Jamu Antihipertensi and captopril are equally effective in patients with hypertension. Universa Medicina, 35(2), 81.

https://doi.org/10.18051/univmed.2016.v35.8 $1-88$

Kemenkes RI. (2019). RISKESDAS 2018.pdf. Lembaga Penerbit Badan Penelitian dan 
511 Sosialisasi Pemanfaatan Herbal Bumbu Dapur sebagai Antihipertensi dan Pemeriksaan Tekanan Darah di Desa Kandangan Baru Kecamatan Panyipatan Tanah Laut - Karina Erlianti, Juwita Ramadhani, Aris Fadillah, Hasniah, Didi Susanto, Muhammad Fauzi, Fauzi Rahman DOI: https://doi.org/10.31004/abdidas.v2i3.311

Pengembangan Kesehatan 2019.

Setianto, R., Dewi, B. A., \& Rosita, F. (2021). Penyuluhan Swamedikasi Obat Herbal Di PKK Kecamatan Dander Kabupaten Bojonegoro. 4(1), 85-93.

Sidoretno, W. ., \& Rz Oktaviani, I. (2018). Edukasi Bahan Kimia Obat Yang Terdapat Di Dalam Obat Tradisional. 1(2), 36-42. https://doi.org/10.36341/jpm.v1i2.453

Stevani, H., Mispari, Dewi, R., \& Setiawati, H. (2020). Penyuluhan Penggunaan Obat Tradisional Kepada Lansia Puskesmas Palanro Kabupaten Barru. Journal Pengabdian Kefarmasian Poltekkes Kemenkes Makasar, 1(1), 23-26. https://doi.org/10.32382/jpk.v1i1.1487

Sumayyah, S., \& Salsabila, N. (2017). Obat Tradisional: Antara Khasiat dan Efek Sampingnya. Farmasetika.Com (Online), 2(5), 1. https://doi.org/10.24198/farmasetika.v2i5.16 780 